\title{
Taming the mammography debate: Screening interval, age of onset, and underdiagnosis
}

\author{
Constantine Kaniklidis* \\ No Surrender Breast Cancer Foundation (NSBCF), USA
}

\section{Commentary}

\section{A Prelude}

In mid-2015 my younger self wrote an editorial in the pages of the Current Oncology journal (titled, fittingly, "Through a glass darkly: the mammography debate") that the mammography debate is (1) "complex; (2) that it is naively implausible to expect any decisive final resolution to the residual issues that will be convincing to the principle contending parties; (3) and that behind it all, the devil is in the methodology" [1]. Below, in this and a series of papers to follow, is the beginning of and early volley towards, that resolution.

\section{The issue of optimal screening interval and age of onset}

A major debate continues, especially in the United States, as to whether the biennial schedule for mammographic screening, which is the current recommendation of the US Preventative Services Task Force (USPSTF), or an annual screening schedule, more favors outcome, and a subsidiary but closely related issue is, for either screening schedule, what is the optimal age to begin screening. To address these issues, we have the results of a study [2] that was conducted based on overall and stage-specific (Stage I through IV) mortality data from the SEER database, to compared three strategies of mammographic screening:

1. the ACR (American College of Radiology) Annual Program (annual screening age 40 and up),

2. the USPSTF (US Preventative Services Task Force) Biennial Program (biennial screening between 50 - 74 years), and

3. the ACS (American Cancer Society) Hybrid Program (annual screening ages 45 to 54 years, thereafter biennially from 55 and above).

What the study found was that the ACR Annual Program had the lowest 5-year estimated overall mortality at $10.1 \%$, being $37.3 \%$ less than the USPSTF Biennial Program and 31.8\% lower than the ACS Hybrid Program. The ACR Annual Program also had the lowest stage I to IV mortality at $12 \%$, being $30.6 \%$ less than the USPSTF Biennial Program and $26.8 \%$ less that the ACS Hybrid Program. These findings show that annual mammographic utilization starting at age 40 as per the ACR Annual Program yields the greatest mortality reduction.

It should be noted that the ACR Annual Program is largely congruent with that of the National Comprehensive Cancer Network (NCCN), the American College of Obstetricians and Gynecologists (ACOG), and the Society of Breast Imaging (SBI); while the USPSTF Biennial Program is (largely) congruent with that of the American Academy of Family Physicians (AAFP) and the American College of Physicians (ACP); and the ACS Hybrid Program is congruent with that of the American Society of Breast Surgeons (ASBS) and the American Society of Clinical Oncology (ASCO). And this solely within the United States, making for no small amount of confusion to the ultimate stakeholder, women seeking screening guidance, who may face a veritable alphabet soup of ACR/NCCN/ACOG/SBI, versus USPSTF/ AAFP/ACP, versus ACS/ASBS/ASCO guidelines and with different practitioners and institutions themselves dividing across these dueling guidelines. For example, the Cleveland Clinic's recommendation is for annual mammographic screening to start at age 45 ; earlier (40-44) is not recommended but rather left to shared decision making between subject and primary care provider [3]. In contrast, Memorial Sloan Kettering Cancer Center (MSKCC) advises annual mammography beginning at 40 for women at average risk, but also for women between the ages of 25 and 40 who are at elevated risk of breast cancer [4]. What's a woman to do confronted with all this? As we see in this paper, there is in fact, if we look closely and critically, more clarity and guidance to offer than has been appreciated.

Toward that end, Martin Yaffe and colleagues at the Sunnybrook Research Institute have recently further shed invaluable light on these issue, by using incidence-based mortality modeling that enables the partitioning of mortality by variables associated with breast cancer onset and thereby provides, by age-at-detection, a quantification of cancer mortality distribution and life-years lost. Their study [5] demonstrates that the largest life-year gains accrue from an annual screening regimen commencing at age 40 . And it should be noted that early data support these conclusions. Thus, a failure analysis study [6] that estimated the impact of mammographic screening on mortality via a review of the screening histories of those women lost to breast cancer, found that the vast majority $(70.8 \%)$ of deaths occurred among the estimated $20 \%$ minority of unscreened women, strongly motivating initiation of annual screening before age 50 to minimize mortality and maximize life-years gained. And Israel Barco and colleagues at the Universitat de Barcelona conducted a prospective multicenter (two) study comparing mammographically screened and nonscreened patients (50- to 69-year-old age group) in relation to age [7]. Based on the results that the screened group exhibited superior prognosis and outcomes compared to all nonscreened groups, and that the younger women in the nonscreened group presented a higher rate of metastasis and a shorter disease-free interval, the investigators posit that extending mammographic screening to include women younger than

${ }^{*}$ Correspondence to: Constantine Kaniklidis, No Surrender Breast Cancer Foundation (NSBCF), USA, Tel: 1-718-622-4626; E-mail: edge@evidencewatch.com

Received: December 06, 2019; Accepted: December 20, 2019; Published: December 24, 2019 
50 (and also those older than 70 years) would likely garner appreciable mortality benefits.

These findings in turn are in agreement with those derived from CISNET (Cancer Intervention and Surveillance Modeling Network) modeling studies. The CISNET modeling studies [8] find an almost $40 \%$ reduction in breast cancer-specific mortality accruing from annual screening, in contrast to just a $23 \%$ reduction associated with the USPSTF Biennial Program. Such BC-specific mortality reduction is in agreement with the conclusions of the IARC (International Agency for Research on Cancer) Working Group's systematic review [9], although we disagree with their [IARC's] claim that the gains primarily affect the 50-69 year old age band, and the evidence we have marshaled in this paper contradicts that viewpoint, which to be fair however was published after the IARC review.

Indeed, as Stephan Feig (UC-Irvine) has recently noted [10], annual screening is especially critical in the $40-49$ age bracket due to the more accelerated tumor doubling time (DT) in that younger group. Using the classical exponential growth model, doubling time rates for breast cancer have been computed using serial ultrasonography, ranging from a short 124 days for triple negative breast cancer (TNBC) tumors, with some high-proliferation index (Ki-67) TNBC tumors exhibiting a doubling time of $<90$ days compared to 185 days for more indolent hormone-positive (ER-positive/HER2-negative) tumors [11]. These are sobering numbers that motivate tighter screening frequency to help detect more aggressive faster growing tumors, and age-dependencies that have independently been verified showing the median volume doubling time of primary breast cancer tumors in women younger than 50 years of age to be almost double that of in women aged 50-70 years further demand a shorter screening interval to reduce number of interval cancers in the younger age group [12].

And although it must be granted that both treatment advances and mammographic screening have played critical roles in observed declines in breast cancer mortality, nonetheless as shrewdly observed by Sylvia Plevritis and colleagues [13], at no time going forward, even in a future utopia of curative success of all breast cancers, are the benefits of screening other than highly consequential since only screening can detect breast cancers at earlier stages than without screening, and early detection significantly reduces the morbidities and QoL-compromising effects of therapeutic interventions whether they be surgical, or treatment-related, compared with presentation at more advanced disease stages. As to the distribution of benefit stemming from screening versus treatment, the Swedish Two-County Screening Evaluation Research Group [14] interrogated five decades of continuous data in a stable population spanning the prescreening and postscreening and adjuvant therapy periods, finding not only significant reductions in breast cancer-specific incidence-based mortality, but that these reductions from screening exposure were independent of concurrent changes in treatment [14]. The very same therapies therefore are seen to be more efficacious in tumors detected at screening than in those in women not participating in screening, so screen-detected tumors would appear to better leverage, compared to their non-screened counterparts, the relevant treatment regimens, a selective advantage.

\section{Degree of premature mortality reduction from mammographic screening participation}

László Tabár at Central Hospital, Falun (Sweden) and colleagues have recently powerfully clarified and quantified the degree of premature mortality reduction from mammographic screening participation [15] culled from over six decades of individual-based data, using the incidence of fatal breast cancer as a novel metric of the impact of earlier diagnosis attributable to mammography screening on screening participants (screen-detected and interval cancers combined) compared with non-participants. This is a more frontal attack using innovative methodology than we have seen to date. The results find a $60 \%$ lower risk of dying from breast cancer within 10 years post-diagnosis and a $47 \%$ lower risk of dying from breast cancer within 20 years post-diagnosis when compared with the corresponding risks for screening nonparticipants. This ingenuous method avoids the contentious issue of overdiagnosis, since in an investigation of fatal cancers, there can be no overdiagnosed breast cancer, all overdiagnosed cancers being definitionally non-fatal. In addition, there are further gains from the methodology used, namely that the use of incidence of fatal cancer coupled with such a long-term follow-up virtually nullifies any length bias while also substantially reducing the influence of leadtime bias.

Also of particular note: that independent of advances in breast cancer therapies, mammographic screening participants reap the advantages of earlier detection and of a greater consequent benefit from less aggressive treatment than do non-participants. In earlier research, these same investigators have made a compelling argument that the incidence of advanced stage breast cancer constitutes a reliable early surrogate indicator of the impact of mammographic service screening, whose goal should be the reduction of risk of receiving a diagnosis of an advanced breast cancer [16]. The authors note that the longer 20-year follow-up period is particular suited to serve as a reliable indicator of the eventual fate of most breast cancer patients, because it has been demonstrated that approximately $95 \%$ of deaths from breast cancer occur within 20 years of diagnosis. From both these studies [15] [16] we can conclude that screening participants obtain a significantly greater benefit from therapy at time of diagnosis than screening nonparticipants, and that the harms of not screening, namely increased risk of breast cancer specific mortality, increased incidence of advanced cancers and associated morbidity, and significant compromise to patient QoL, along with attenuated benefit from the same treatment as compared to screening participants, generate a highly unfavorable benefit-to-harm ratio for not screening, one that must be explicitly recognized beyond the to-date current focus on solely the benefitto-harm ratio of screening. We must also grant the perspective of the ultimate stakeholder, screening-eligible women, where as I have noted women express an overriding preference to err on the side of caution and frankly prefer the risk of overtreatment to the risk of undertreatment [17-19]. As I also noted in agreement with the insights of commentator Lisa Rosenbaum [20] who suggested a preference to avoid regret, rather than anxiety, in making screening decsions, there is a strong element of regret-minimization by electing potential overtreatment above the value of undertreatment, a preference validated recently in a national survey in the U.S. [21]. Moreover, the studies of László Tabár $[15,22]$ contradict an entrenched view that mammographic screening serves only the identify non-life-threatening clinically insignificant or slowly growing cancers while missing potentially fatal more aggressive tumors, and these and the others studies reviewed here $[2,5-7,10,13]$, and elsewhere $[23,24]$ along with the recent findings of Sarah Moorman and Akshat Pujara [25], discussed immediately below, demonstrate the opposite.

Finally, we have late-breaking (Dec 4, 2019) further confirmation from new findings of a retrospective study from the team of Sarah 
Moorman and Akshat Pujara and colleagues at Michigan Medicine / University of Michigan on the morbidity of breast cancer as a function of screening interval (Annual versus Biennial) presented at the 2019 Annual Meeting of the Radiological Society of North America (RSNA) [25] held in Chicago December 1-6, 2019. We find that these are the most important major results presented:

1. Annual screening yields fewer advanced stage breast cancers (24\%) compared with biennial screening (43.8\%).

2. Annual screening mammography also results in fewer interval cancers (10.5\%) compared biennial screening (38\%).

3. Mean tumor size was significantly smaller $(1.4+2 \mathrm{~cm})$ in the annual screening patients compared with those undergoing biennial screening $(1.8+1.6 \mathrm{~cm})$.

Collectively, these findings again confirm that screening mammography performed at less than annual frequency is prognostically inferior to annual screening and is associated with increased patient morbidity, and the need for more aggressive treatment (there were trends for less frequent axillary lymph node dissection and chemotherapy use with annual screening but these nonetheless failed to reach statistical significance). Note that controls were methodologically tight in that the two groups - annual versus biennial screening patients had comparable baseline characteristics (age, menopausal status, family history, race, and hormone replacement use).

And from another but related perspective we must remember that these are the vital but widely underappreciated harms of not screening and must figure in any calculus of the benefit/harm equation of screening, and not screening [26,27], a term for which we have used the concept of "underdiagnosis" $[17,28]$. The harm of underdiagnosis stems from a progressive decline in survival consequent to each annual mammography screening that is omitted: thus, one study found that women who had missed any of their previous 5 annual screenings incurred more than a doubling of risk for all-cause mortality compared with women having no missed screenings, the hazard ratio becoming statistically significant at even just 2 annual missed exams, decisively arguing against a biennial schedule [29]. On the other side of the coin, Martin Yaffe and colleagues elucidate the many benefits beyond mortality that include, among others, gain in quality-adjusted lifeyears and reduction of treatment-related morbidities [27]. These benefits and may also encompass surgical benefits in the form of lower rates of metastatic lymph node-positive disease and of axillary lymph node dissection, and higher rates of breast-conserving surgery (BCS) avoiding mastectomy, in general assuring higher likelihood of less invasive surgery [30,31].

\section{An Imperative}

For screening advocates like Daniel Kopans at Harvard [32] and László Tabár at Central Hospital, Falun (Sweden) [33], the manifest mortality benefits overwhelm the low incidence of potential and generally tolerable - harms (largely claimed stemming from overdiagnosis), and for these and many other researchers and clinicians, the data entails for them not a traditional faith-based imperative, but rather what I term an evidence-based moral imperative to not only call for, but demand, comprehensive early (by age 40) annual mammographic screening to save thousands of lives and spare countless women (and men) the morbidities associated with the late detection of more advanced breast cancers. At the dawn of 2020, the evidence is clear. So should be our responsibility.

\section{References}

1. Kaniklidis C (2015) No Surrender Breast Cancer Foundation. Through a glass darkly: the mammography debate. Curr Oncol 22: 171-173. [Crossref]

2. Patel SB (2018) Estimated Mortality of Breast Cancer Patients Based on Stage at Diagnosis and National Screening Guideline Categorization. J Am Coll Radiol 15: 1206-1213. [Crossref]

3. Disease Management: Breast Disorders, Cancer Screening, and Risk Assessment Cleveland Clinic Center for Continuing Education. Available from: http://www. clevelandclinicmeded.com/medicalpubs/diseasemanagement/womens-health/breastdisorders-cancer-screening-and-risk-assessment/default.htm

4. Breast Cancer Screening Guidelines. Memorial Sloan Kettering Cancer Center Available from: https://www.mskcc.org/cancer-care/types/breast/mammogramsbreast-exams/screening-guidelines-breast

5. Yaffe MJ, Mittmann N, Alagoz O, Trentham-Dietz A, Tosteson AN, et al. (2018) The effect of mammography screening regimen on incidence-based breast cancer mortality. J Med Screen 25: 197-204. [Crossref]

6. Webb ML, Cady B, Michaelson JS, Bush DM, Calvillo KZ, et al. (2017) A failure analysis of invasive breast cancer: most deaths from disease occur in women not regularly screened. Cancer 120: 2839-2846. [Crossref]

7. Barco I, Chabrera C, García Font M, Gimenez N, Fraile M, et al. (2015) Comparison of Screened and Nonscreened Breast Cancer Patients in Relation to Age: A 2-Institution Study. Clin Breast Cancer 15: 482-489. [Crossref]

8. Arleo EK, Hendrick RE, Helvie MA, Sickles EA (2017) Comparison of recommendations for screening mammography using CISNET models. Cancer 123: 3673-3680. [Crossref]

9. Lauby-Secretan B, Scoccianti C, Loomis D, Benbrahim-Tallaa L, Bouvard V, et al (2015) Breast-Cancer Screening - Viewpoint of the IARC Working Group. $N$ Engl J Med 372: 2353-2538. [Crossref]

10. Feig S (2019) Evidence of Benefit from Mammography Screening of Average-Risk Women Ages 40-49 Years: Science, Metrics, and Value Judgments. J Breast Imaging 1: $78-83$

11. Nakashima K, Uematsu T, Takahashi K, Nishimura S, Tadokoro Y, et al. (2019) Does breast cancer growth rate really depend on tumor subtype? Measurement of tumor doubling time using serial ultrasonography between diagnosis and surgery. Breast Cancer 26: 206-214. [Crossref]

12. Peer PG, van Dijck JA, Hendriks JH, Holland R, Verbeek AL (1993) Age-dependent growth rate of primary breast cancer. Cancer 71: 3547-3551. [Crossref]

13. Plevritis SK, Munoz D, Kurian AW, Stout NK, Alagoz O, et al. (2018) Association of Screening and Treatment With Breast Cancer Mortality by Molecular Subtype in US Women, 2000-2012. JAMA 319: 154-164. [Crossref]

14. Smith R, The Swedish Two-County Screening Evaluation Research Group (2018) Participation in Mammography Screening Accomplishes an Enduring and Significant Reduction in Breast Cancer Mortality in the Era of Modern Therapy: An Observational Study Spanning 52 Years. J Global Oncol 4: 56s.

15. Tabár L, Dean PB, Chen TH, Yen AM, Chen SL, et al. (2019) The incidence of fatal breast cancer measures the increased effectiveness of therapy in women participating in mammography screening. Cancer 125: 515-523. [Crossref]

16. Tabár L, Yen AM, Wu WY, Chen SL, Chiu SY, et al. (2015) Insights from the Breast Cancer Screening Trials: How Screening Affects the Natural History of Breast Cancer and Implications for Evaluating Service Screening Programs. Breast J 21: 13-20. [Crossref]

17. Kaniklidis C, No Surrender Breast Cancer Foundation (2015) Beyond the mammography debate: a moderate perspective. Curr Oncol 22: 220-229. [Crossref]

18. Waller J, Douglas E, Whitaker KL, Wardle J (2013) Women's responses to information about overdiagnosis in the U.K. breast cancer screening programme: a qualitative study. BMJ Open 3: e002703.

19. Kaniklidis C (2015) Mammography, Martin Yaffe, and me: response and appreciation Curr Oncol 22: e404-e408.

20. Rosenbaum L (2014) Invisible risks, emotional choices-mammography and medical decision making. N Engl J Med 371: 1549-1552. [Crossref]

21. Qin X, Nagler RH, Fowler EF, Gollust SE (2019) U.S. women's perceived importance of the harms and benefits of mammograms and associations with screening ambivalence: Results from a national survey. Prev Med 123: 130-137. [Crossref] 
22. Tabár L, Chen TH, Yen AM, Chen SL, Fann JC, et al. (2018) Effect of mammography screening on mortality by histological grade. Cancer Epidemiol Biomarkers Prev 27: 154-157. [Crossref]

23. Duffy SW, Chen TH, Smith RA, Yen AM, Tabar L. (2013) Real and artificial controversies in breast cancer screening: a perspective article. Breast Cancer Manage 2: $519-528$.

24. Destounis S, Santacroce A (2018) Age to Begin and Intervals for Breast Cancer Screening: Balancing Benefits and Harms. AJR Am J Roentgenol 210: 279-284. [Crossref]

25. Biennial Mammography Screening Yields More Advanced-Stage Cancers (2019) Radiological Society of North America. RSNA Press Release. Available from: http:// press.rsna.org/timssnet/media/pressreleases/14_pr_target.cfm?ID=2123

26. Costanza ME (2015) Has screening mammography become obsolete? Curr Oncol 22: e328-e331. [Crossref]

27. Yaffe MJ, Jong RA, Pritchard KI (2019) Breast Cancer Screening: Beyond Mortality. J Breast Imaging 1: 161-165.
28. Kaniklidis C (2017) Overdiagnosis, Overdone: Unraveling Issues and Pitfalls. Cancer Knowledge Network. Breast Cancer Screening Series: Available from: https://cancerkn. com/breast-cancer-screening-series-constantine-kaniklidis/\#more-12568.

29. Engel JM, Stankowski-Drengler TJ, Stankowski RV, Liang H, Doi SA, et al. (2015) Allcause mortality is decreased in women undergoing annual mammography before breast cancer diagnosis. AJR Am J Roentgenol 204: 898-902. [Crossref]

30. Fancellu A, Sanna V, Sedda ML, Delrio D, Cottu P, et al. (2019) Benefits of Organized Mammographic Screening Programs in Women Aged 50 to 69 years: A Surgical Perspective. Clin Breast Cancer 19: e637-e642. [Crossref]

31. Elder K, Nickson C, Mann GB (2018) ASO Author Reflections: Impact of Breast Cancer Screening Beyond Mortality Reductions. Ann Surg Oncol 25: S687-S688. [Crossref]

32. Kopans DB (2018) Breast cancer screening: Where have we been and where are we going? A personal perspective based on history, data and experience. Clin Imaging 50: 91-95. [Crossref]

33. Tabár L, Dean PB (2019) The so-called "debate" over breast cancer screening is not true debate. Cancer Knowledge Network. Breast Cancer Screening Series: Drs. László Tabár \& Peter Dean. Available from: https://cancerkn.com/breast-cancer-screeningseries-drs-laszlo-tabar-peter-dean/

Copyright: $@ 2019$ Kaniklidis C. This is an open-access article distributed under the terms of the Creative Commons Attribution License, which permits unrestricted use, distribution, and reproduction in any medium, provided the original author and source are credited. 